\title{
Article \\ Hair-Growth-Promoting Effects of Fermented Red Ginseng Marc and Traditional Polyherb Formula in C57BL/6 Mice
}

\author{
Phil Hyun Song ${ }^{1,+}$, Gyu-Ryeul Park ${ }^{2,+}$, Yoon-Hae Kim ${ }^{3}$, Dae Hwa Jung ${ }^{4}$, Sae-Kwang Ku ${ }^{2,4, *(D)}$ and \\ Chang-Hyun Song $2,4, *$
}

Citation: Song, P.H.; Park, G.-R.; Kim, Y.-H.; Jung, D.H.; Ku, S.-K.; Song, C.-H. Hair-Growth-Promoting Effects of Fermented Red Ginseng Marc and Traditional Polyherb Formula in C57BL/6 Mice. Appl. Sci. 2021, 11, 1195. https://doi.org/ 10.3390/app11031195

\section{Academic Editor:}

Alessandra Durazzo

Received: 31 December 2020

Accepted: 25 January 2021

Published: 28 January 2021

Publisher's Note: MDPI stays neutral with regard to jurisdictional claims in published maps and institutional affiliations.

Copyright: (C) 2021 by the authors. Licensee MDPI, Basel, Switzerland. This article is an open access article distributed under the terms and conditions of the Creative Commons Attribution (CC BY) license (https:// creativecommons.org/licenses/by/ $4.0 /)$.
1 Department of Urology, College of Medicine, Yeungnam University, Daegu 42415, Korea; sph04@hanmail.net

2 Department of Anatomy and Histology, College of Korean Medicine, Daegu Haany University, Gyeongsan 38610, Korea; 9027187@dhu.ac.kr

3 Pung-gi Ginseng Production Farming Cooperation, Yeongju 689-822, Korea; seakim88@daum.net

4 Department of Pharmaceutical Engineering, Daegu Haany University, Gyeongsan 38610, Korea; jdh8024@daum.net

* Correspondence: gucci200@hanmail.net (S.-K.K.); dvmsong@dhu.ac.kr (C.-H.S.); Tel.: +82-53-819-1549 (S.-K.K.); +82-53-819-1822 (C.-H.S.)

+ P.H.S. and G.-R.P. contributed equally to this.

\begin{abstract}
An abnormal hair-growth cycle induces hair loss, which affects psychological distress and impairs life quality. Red ginseng marc (RGM) is usually discarded as a byproduct after extracting red ginseng, but several studies have shown that the RGM still has bioactive components including ginsenosides. Therefore, the hair-growth effects of fermented RGM (fRGM) and traditional polyherb formula $(\mathrm{PH})$ were examined in C57BL/6 mice. The dorsal hairs of mice were depilated, and they were topically treated with fRGM or PH at 400, 200 and $100 \mathrm{mg} / \mathrm{kg}$ or the combination of both middle doses (combi) once a day for two weeks. The hair-covering regions were significantly increased with higher doses of fRGM and PH and in combi groups, compared with the control treated with distilled water. Hair length, thickness and weight also increased in the treatment groups. In particular, the fRGM and PH increased the anagen-phased hair follicles, the follicular diameters and the dermal thickness. Immunostains for Ki-67 showed the anagen-phased cell division in the treatment groups. The beneficial effects were greater in the high doses of fRGM and PH and the combi groups. These suggest hair-growth-promoting effects of fRGM, PH and the combination by enhancing the hair-growth cycle.
\end{abstract}

Keywords: hair growth; growth cycle; red ginseng marc; polyherb; hair length; hair thickness; hair weight; proliferation; anagen

\section{Introduction}

Scalp hair has an important psychosocial function related to human appearances, as well as functions in insulation and protection. The hair normally sheds up to 100 a day [1], and the hair follicle constantly undergoes the specific growth cycle characterized by anagen (growth phase), catagen (regression phase) and telogen (resting phase) [2]. The hair-growth cycle is regulated by growth factors, cytokines and hormones; however, the altered growth cycle can cause hair loss. The most common hair losses related to the abnormal growth cycle are androgenetic alopecia and chronic alopecia areata $[3,4]$. The other factors include heredity, aging, medication and psychological stress [4]. Hair loss is not considered a life-threatening condition; however, it causes psychological distress and impairment of life quality [4,5]. In this context, the treatment is a major concern for the cosmetologists and dermatologists. Until now, finasteride (as a 5 - $\alpha$ reductase type II inhibitor) and minoxidil (as an antihypertensive vasodilator) have been approved by the Food and Drug Administration (FDA) of the United States for hair growth [6]. Although the drugs promote the anagen phase, they have some side effects, in particular in finasteride 
(i.e., reduced libido, erectile dysfunction and gynecomastia), and the effectiveness varies greatly among individuals [7]. Therefore, there is an urgent need to develop treatments that prevent hair loss and promote hair growth.

Ginseng (Panax ginseng C.A. Meyer) has long been used as a traditional herbal medicine in Eastern Asia. Red ginseng is a steamed root of the ginseng that is harvested after six years, and the extracts have shown various pharmacological properties such as antioxidant, anti-stress, antitumor, antimutagenic, antidiabetic and immunomodulatory activities $[8,9]$. The red ginseng has been reported to promote hair growth in animal models by preventing apoptosis of hair follicle cells and inhibiting $5-\alpha$ reductase $[10,11]$. It also increases the hair follicle density and size in the patients with androgenetic alopecia [12]. The functional main ingredients are saponins (ginsenosides), polysaccharides and phenolic compounds. In particular, ginsenosides increase epithelial cell genesis/development and endothelial progenitor cell migration/proliferation [13], and they also involve promoting hair growth through anti-apoptotic effects [14,15]. Furthermore, some components composing traditional polyherb formulas used for treating hair loss have been proved to have promoting effects on hair growth, even though the combination effects remain to be clarified: Cornu cervi pantotrichum facilitates hair growth through upregulation of fibroblast growth factor (FGF)-7 [16]; Eclipta prostrata stimulates the anagen phase through regulation of FGF-7 and -5 [17]; Dictamnus dasycarpus Turczaininov, Polygonum multiflorum Thunberg and Lycopus lucidus Turczaininov are often used in combination for the herbal formulas in alopecia [18]. In addition, Eclipta prostrata and Polygonum multiflorum Thunberg have significant inhibitory activities against 5- $\alpha$ reductase [19].

Red ginseng marc (RGM) is a byproduct obtained after extracting the red ginseng, which is usually discarded as waste. However, RGM or fermented RGM has shown antioxidant, immunomodulatory and anticancer effects [20,21]. It is believed that the bioactive components including ginsenosides and polysaccharides contained in RGM are still effective despite small amounts [20,22]. Moreover, the fermentation process of RGM enhances the beneficial effects, especially strong antioxidant and anti-inflammatory effects [23]. Effective microorganism (EM) is a complex of microorganisms including photosynthetic bacteria, lactic acid bacteria and yeast, and various natural products fermented with EM enhance the antioxidant, anti-inflammatory, anticancer, anti-stress and neuroprotective effects [24-26]. In the present study, the extracts of RGM fermented with EM contained ginsenosides including Rb1, Rb2, Rb3, Rc, Rd, Re, Rf, Rg2, Rg3 and Rh1. Among them, Rb1 and $\mathrm{Rd}$ have been reported to prevent hair loss and stimulate proliferation of hair follicle cells $[15,27]$. Therefore, to find out whether the fermented type of RGM (which is generally considered useless), traditional polyherb formula (which is traditionally used for treating hair loss, but there is a lack of scientific evidence) can actually enhance hair growth, and whether the combination can have the synergic effects, we examined the promoting effects in hair-removed C57BL/6 mice.

\section{Materials and Methods}

\subsection{Preparation of Fermented RGM and Traditional Polyherb Formula}

Fermented RGM was provided by Punggi Ginseng Farming Corp. (Yeongju, Korea). Briefly, after red ginseng was extracted by boiling with distilled water (DW) for $3 \mathrm{~h}$ at $80^{\circ} \mathrm{C}$, the remaining RGM was dried and grinded. The powder-form of RGM was fermented with EM containing Lactobacillus casei, Saccharomyces cerevisiae and Rhodobacter capsulatus (Ever Miracle ${ }^{\mathrm{TM}}$, Ever Miracle Co., Ltd., Jeonju, Korea) in DW at $45^{\circ} \mathrm{C}$ for 15 days. Then, it was extracted by boiling three times in DW for $3 \mathrm{~h}$ at $80^{\circ} \mathrm{C}$. The yield efficiency was $40.5 \%$. The extracts of fermented RGM (fRGM) were lyophilized. The components of fRGM were analyzed based on a standard of the Korean FDA: For ginsenosides, the powder of fRGM was dissolved in 80\% ethanol and analyzed using an Agilent 1100 high-performance liquid chromatography (HPLC) with Agilent C18 column under the standard curves for Rg1, Re, Rf, Rg2, Rh1, Rb1, Rc, Rb2, Rb3, Rd, Rg3 and Rh2. For soluble sugars and polysaccharides, the powder was incubated in $80 \%$ ethanol at $80{ }^{\circ} \mathrm{C}$ for $30 \mathrm{~min}$ and centrifuged at $4000 \times g$ 
for $20 \mathrm{~min}$. The supernatant was mixed with $2 \%$ anthrone-ethyl acetate and $98 \% \mathrm{H}_{2} \mathrm{SO}_{4}$ for sugars. The precipitates were homogenized in $1 \mathrm{~mol} / \mathrm{L} \mathrm{HCl}$ for the polysaccharides and then neutralized with $10 \% \mathrm{NaOH}$, followed by centrifuging at $4000 \times g$ for $10 \mathrm{~min}$. The supernatants were measured at $630 \mathrm{~nm}$ under the standard curve using D-glucose. For carbohydrates, the powder of fRGM was incubated with $1 \mathrm{~mol} / \mathrm{L} \mathrm{NaOH}$ in anhydrous ethanol at $80{ }^{\circ} \mathrm{C}$ for $10 \mathrm{~min}$ and centrifuged at $4000 \times \mathrm{g}$ for $10 \mathrm{~min}$. The supernatants were incubated with $0.09 \mathrm{~mol} / \mathrm{L} \mathrm{NaOH}, 1 \mathrm{~mol} / \mathrm{L}$ acetic acid and $10 \%$ iodine solution for $10 \mathrm{~min}$, and the absorbance was measured at $580 \mathrm{~nm}$. The contents for $\mathrm{Pb}, \mathrm{As}, \mathrm{Hg}, \mathrm{Sb}$ and $\mathrm{Cd}$ were analyzed using an HPLC system under their standard curves. The potential toxic substances were examined by the Korea Conformity Laboratories (Seoul, Korea) as a certified material test report. All medicinal herbs composing traditional polyherb formula (PH) were purchased from Omniherb pharmacy (Jecheon, Korea) and are listed in Table 1. The fRGM and PH were dissolved in DW and stored at $4{ }^{\circ} \mathrm{C}$ until use.

Table 1. Composition of traditional polyherb formula used here.

\begin{tabular}{ccc}
\hline Herbs & Scientific Name & Amounts \\
\hline Pilose Antler & Cornu cervi pantotrichum & $20 \%$ \\
Old Antler & Cornu cervi & $60 \%$ \\
Ecliptae Herba & Eclipta prostrata L. & $1 \%$ \\
Dictamni Radicis Cortex & Dictamnus dasycarpus Turczaininov & $2 \%$ \\
Polygoni Multiflori Radix & Polygonum multiflorum Thunberg & $8 \%$ \\
Lycopi Herba & Lycopus lucidus Turczaininov & $8 \%$ \\
Red ginseng & Panax ginseng C. A. Meyer & $1 \%$
\end{tabular}

All of the medicinal herbs were purchased from Omniherb Co, Ltd. (Jecheon, Korea). The amounts of herbs were expressed as percentages contained in a polyherb formula.

\subsection{Animal}

All experiments were conducted according to the national regulations of the usage and welfare of laboratory animals and approved by the Daegu Haany University-Institutional Animal Care and Use Committee (Gyeongsan, Korea, approval number: DHU2015-019). Six-week-old male C57BL/ 6 mice were purchased from OrientBio (Seungnam, Korea). The mice were housed in a temperature- $\left(20-25^{\circ} \mathrm{C}\right)$ and humidity- $(40-45 \%)$ controlled room, with a light/dark cycle of 12/12 h. Feed and water were supplied ad libitum. Animals were acclimatized for 2 weeks (Figure 1).

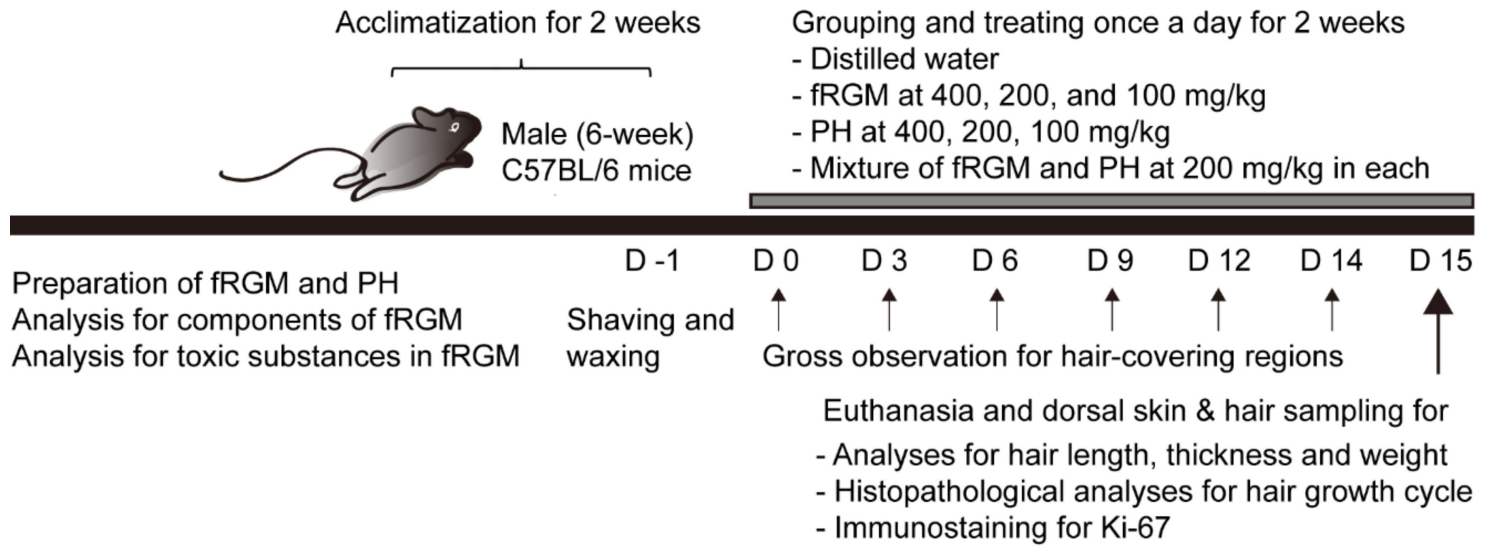

Figure 1. A scheme of study design. Hair-removed model was topically treated with fermented red ginseng marc (fRGM) or traditional polyherb formula (PH) at 400, 200 and $100 \mathrm{mg} / \mathrm{kg}$, or the combination at $200 \mathrm{mg} / \mathrm{kg}$ of fRGM and PH in each (combi). The results were compared with those of the control group treated with distilled water (DW). 


\subsection{Hair Removal and Treatments}

The dorsal skin hairs of mice were shaved completely using an electric clipper and a hair waxing cream containing $80 \%$ thioglycolic acid (NiClean ${ }^{\mathrm{TM}}$, Ildong Pharmaceutical Co., Seoul, Korea) for inducing anagen synchronization, as described elsewhere [28-30]. The next day, a total of 48 mice was divided into eight groups ( $n=6$ per group) based on their body weights; a control group with DW as a vehicle (DW), six treatment groups with fRGM (fRGM400, fRGM200 and fRGM100) or PH (PH400, PH200 and PH100) at three different doses of 400, 200 and $100 \mathrm{mg} / \mathrm{kg}$ in DW. One group was for a combination group with fRGM and PH at $200 \mathrm{mg} / \mathrm{kg}$ in each (combi). Treatments were topically applied on the dorsal-hair-removed area of approximately $3 \times 5 \mathrm{~cm}^{2}$ in a volume of $200 \mu \mathrm{L}$ per mouse, once a day for 2 weeks.

\subsection{Macroscopic and Microscopic Assessment}

The dorsal skin image was obtained using a digital camera, and hair growth was assessed as darkening of the dorsal skin, as described previously [28,29]. After treatments for 2 weeks, mice were euthanized using $\mathrm{CO}_{2}$ gas, and the dorsal skin area was sampled. The half of the samples with hairs were weighed, and the hairs were carefully plucked. Among the hairs, ten hairs per a mouse were collected, and hair length and thickness were assessed under microscopy [31]. They were analyzed using a computer-based image analysis program (iSolution FL ver 9.1, IMT i-solution Inc., Vancouver, BC, Canada). In addition, hair weight was calculated by subtracting the weight of hair-removed skin samples from that of the samples with hairs. Then, the other samples close to the neck were subjected to histopathological analyses.

\subsection{Histopathology}

The skin sample was fixed in $10 \%$ neutral buffered formalin and trimmed crossly and longitudinally based on the sagittal axis of a mouse body. The paraffin-embedded samples were serially sectioned at a thickness of $3 \mu \mathrm{m}$. The sections were stained with hematoxylin and eosin (H\&E) or immunostained [32]. In H\&E stain, histomorphometric analyses were examined for dermal thickness ( $\mu \mathrm{m} / \mathrm{skin}$ ) and numbers of hair follicles (follicles $/ \mathrm{mm}^{2}$ ) in the cross sections, and hair shafts and follicular sizes with hair root sheath $(\mu \mathrm{m} /$ follicle) in the longitudinal sections, using an image analysis program (iSolution FL ver 9.1, IMT i-solution Inc.), as described previously $[28,30]$. The analyses were performed at least in three histological fields in each section by a histopathologist blinded to the groups.

\subsection{Immunohistochemistry}

The serial sections were de-paraffinized and conducted for citrate buffer antigen retrieval pretreatment, as described previously [32]. Briefly, the sections were heated in $10 \mathrm{mM}$ citrate buffers ( $\mathrm{pH}$ 6.0) at $95-100{ }^{\circ} \mathrm{C}$ for $20 \mathrm{~min}$. They were fixed in methanol for $30 \mathrm{~min}$ and then blocked with normal horse serum solution (1:100, Vector Laboratories, Burlingame, CA, USA) for $1 \mathrm{~h}$. The sections were incubated with a mouse anti-Ki-67 antibody (ab6526, 1:200, Abcam, Cambridge, UK) overnight at $4{ }^{\circ} \mathrm{C}$, and then with Alexa Fluor 488-conjugated goat anti-mouse IgG (1:2000, Molecular Probes, Eugene, OR, USA) for $1 \mathrm{~h}$, followed by mounting with Vectashield ${ }^{\mathrm{TM}}$ containing 4,6-diamidino-2-phenylindole (Vector Laboratories). The immunostains were performed in a humidity chamber, and sections were rinsed in 0.01 M PBS three times between each step. The Ki-67 antibodyomitted stains were used as a negative control. Hair follicle cells occupied by over $30 \%$ of immunofluorescence were regarded as positive cells. The immunostained cells were expressed as a percentage of total follicle cells more than 100 in the cross and longitudinal sections to the craniocaudal axis of mice. It was assessed by a histopathologist blinded to the groups. 


\subsection{Statistical Analyses}

All data were expressed as means \pm standard error (SEM) of six sample sizes. Variance homogeneity was examined using the Levene test. Since the test indicated no significant deviations, the data were analyzed by one-way analysis of variance (ANOVA), followed by Tukey post hoc test. The kinetic changes on hair growth were examined by two-way ANOVA with main factors for the group and the day measured, and the day was treated as repeated measurements. A $p<0.05$ was considered significant.

\section{Results}

\subsection{Components of $f R G M$}

The fRGM contained $0.2 \mathrm{~g} / \mathrm{mL}$ carbohydrates and $0.1 \mathrm{~g} / \mathrm{mL}$ saccharides; however, fats including saturated and trans-fat and cholesterol were not detected. It had crude ginsenosides of $1.71 \mathrm{mg} / \mathrm{g}$ and polyphenols of $9.82 \pm 0.03 \mathrm{mg} / \mathrm{g}$. The contained ginsenosides were $\mathrm{Rb} 1(0.6 \mathrm{mg} / \mathrm{kg}), \mathrm{Rb} 2(0.9 \mathrm{mg} / \mathrm{kg}), \mathrm{Rb} 3(1.8 \mathrm{mg} / \mathrm{kg}), \mathrm{Rc}(1.9 \mathrm{mg} / \mathrm{kg}), \mathrm{Rd}(3.5 \mathrm{mg} / \mathrm{kg})$, $\operatorname{Re}(3.1 \mathrm{mg} / \mathrm{kg}), \operatorname{Rf}(3.9 \mathrm{mg} / \mathrm{kg}), \operatorname{Rg} 2(12.1 \mathrm{mg} / \mathrm{kg}), \operatorname{Rg} 3(9.6 \mathrm{mg} / \mathrm{kg})$ and $\mathrm{Rh} 1(17.9 \mathrm{mg} / \mathrm{kg})$. The potential toxic substances, such as $\mathrm{Pb}, \mathrm{As}, \mathrm{Hg}$, $\mathrm{Sb}$ and $\mathrm{Cd}$, were few under detection.

\subsection{Effects on Hair Growth Region}

The hair was observed a little in all groups until day 6 post-treatment and had markedly grown from day 9 post-treatment regardless of treatments. Although hair growth until day 14 post-treatment showed individual differences even in the same group, it tended to be faster in the treatment groups of fRGM, PH and combi than the DW control (Figure 2). Two-way ANOVA for the kinetic hair growth showed no significances for the groups. There were significances for the days measured $(\mathrm{F}=374.1 ; p<0.01$, Figure 3$)$, representing just daily hair growth. There were no significant interactions between the groups and the days. However, the total hair growth from the initial (day 0 ) to the last treatment (day 15) showed differences among groups $(\mathrm{F}=4.2 ; p<0.01)$. The post hoc versus the DW control revealed significant increases by 1.5-, 1.4-, 1.5- and 1.5-folds in the fRGM400, fRGM200, PH400 and combi groups, respectively $(p<0.05)$.

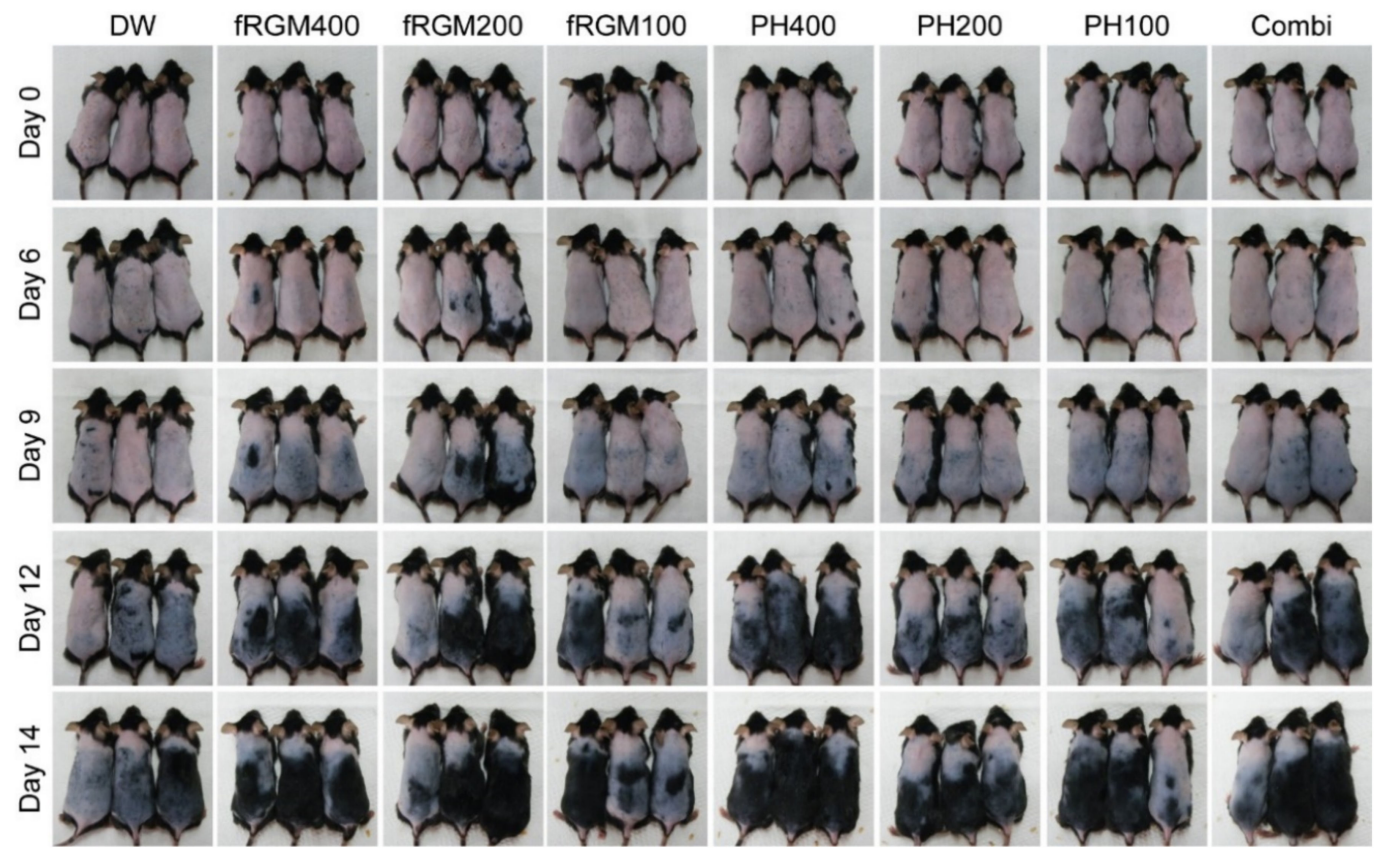

Figure 2. Kinetic changes in hair-covering regions. The representative images for hair-regrown regions in three of six mice per group are shown on days $0,6,9,12$ and 14 after treatments. 

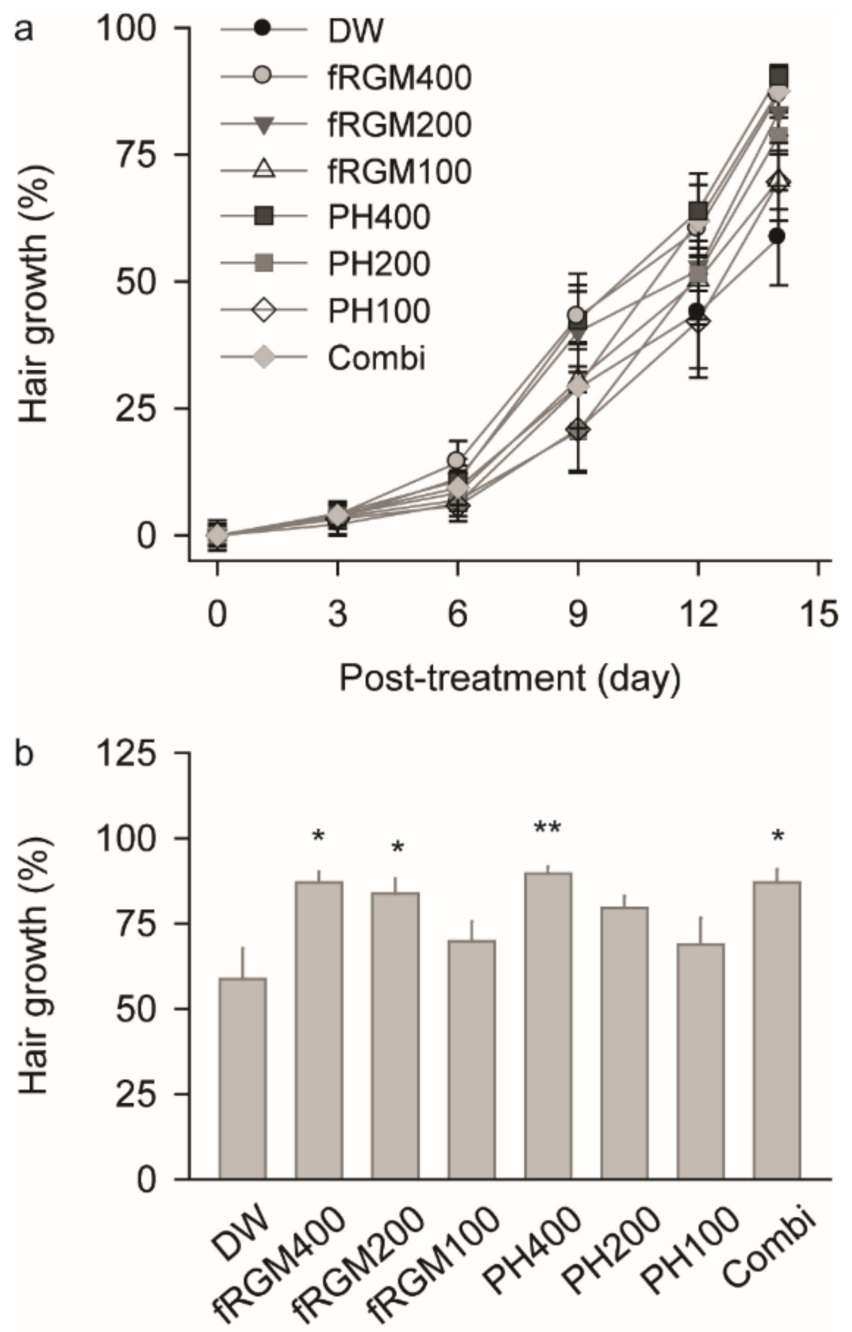

Figure 3. Effects on hair growth. The kinetic changes in hair growth (a) and the total hair growth from the initial to the last treatments $(\mathbf{b})$ were assessed. Values are expressed means \pm SEM of 6 sample sizes. ${ }^{* *} p<0.01$ and ${ }^{*} p<0.05$ versus the DW group.

\subsection{Effects on Hair Length, Thickness and Weight}

Hair length and thickness were increased in all treatment groups comparing to the DW (Figure 4). There were significant differences among the groups for hair length $(\mathrm{F}=15.9$; $p<0.01)$ and thickness $(\mathrm{F}=5.2 ; p<0.01)$. Hair length was significantly increased by 1.3 -fold in the fRGM400, fRGM200 and combi groups and by 1.2-fold in the fRGM100 and PH groups $(p<0.01)$. Hair thickness was increased by 1.4 -fold in the fRGM400 and combi and 1.3-fold in the other treatment groups $(p<0.05)$. There were also significant differences among the groups for hair weight $(\mathrm{F}=3.7 ; p<0.01)$. The post hoc tests versus the DW group revealed significant increases by 2.4-, 2.2-, 2.3-, 2.1 and 2.3-fold in the fRGM400, fRGM200, PH400, PH200 and combi groups, respectively $(p<0.05)$. The weights were also increased by 2.0- and 1.7-fold in the fRGM100 and PH100, respectively; however, they were not significant. 

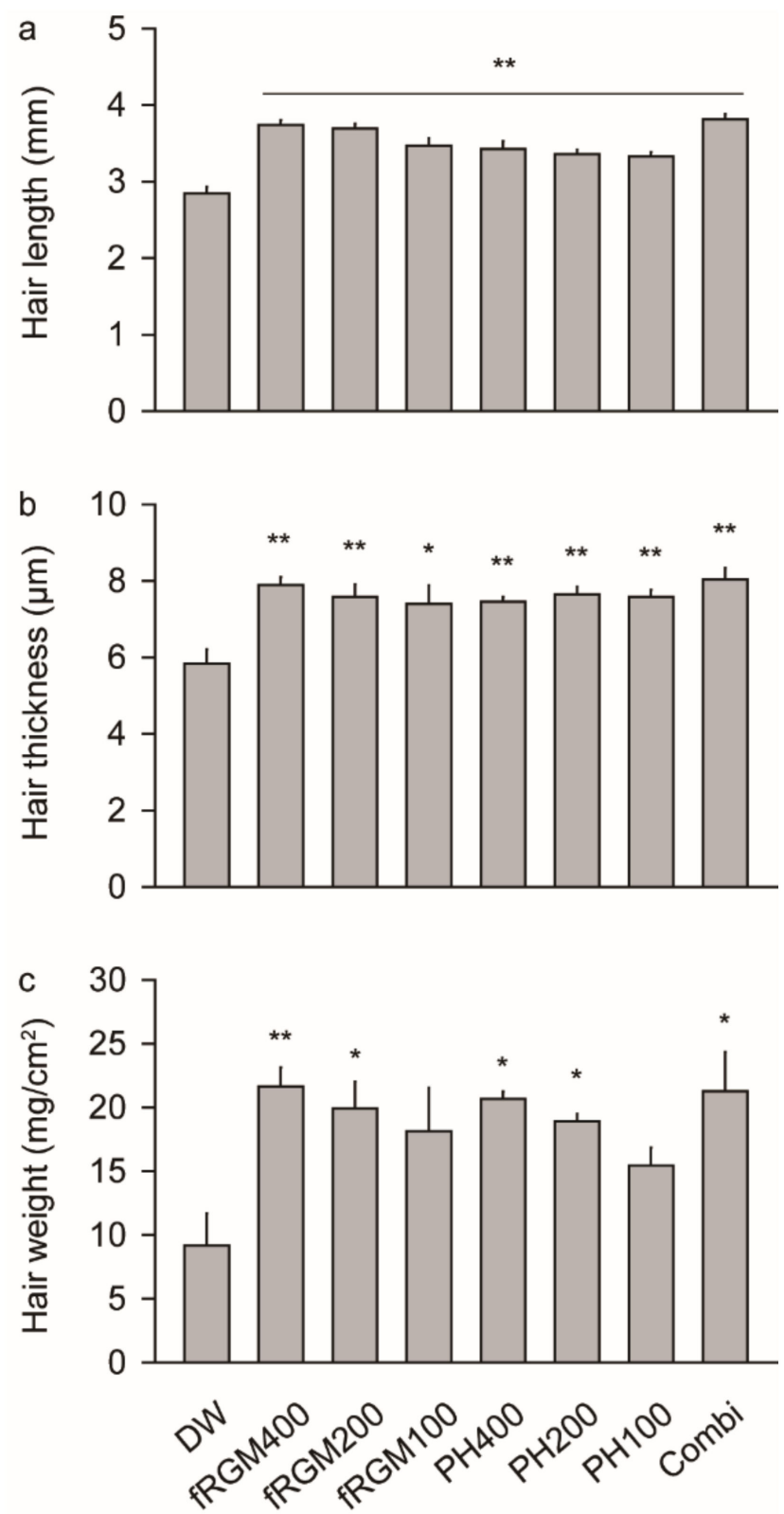

Figure 4. Effects on hair quality. After treatments for 2 weeks, ten hairs per mouse and the dorsal skin tissues were sampled. The hairs were analyzed for the length (a) and thickness (b). Hair weight was measured by subtracting weights of hair-removed samples from those of the samples with hairs and normalized by sample areas (c). Values are expressed as mean \pm SEM of 6 sample sizes. ${ }^{* *} p<0.01$ and ${ }^{*} p<0.05$ versus the DW group.

\subsection{Effects on Development of Anagen-Phased Hair Follicle}

In both cross and longitudinal sections stained with H\&E stain, the dermal thickness was increased in the treatment groups of fRGM, PH and combi than the DW control. Number of the follicles, especially in follicles located at the lower subcutis, and the follicular diameters were also observed as increased in the treatment groups (Figure 5). One-way ANOVA showed significant differences among the groups for the dermal thickness $(\mathrm{F}=3.4$; $p<0.01)$ and the follicular sizes $(\mathrm{F}=4.1 ; p<0.01)$. For both data, the post hoc tests versus the DW group revealed significant increases by 1.2-fold in the fRGM400, fRGM200, PH400, PH200 and combi groups $(p<0.05)$. 

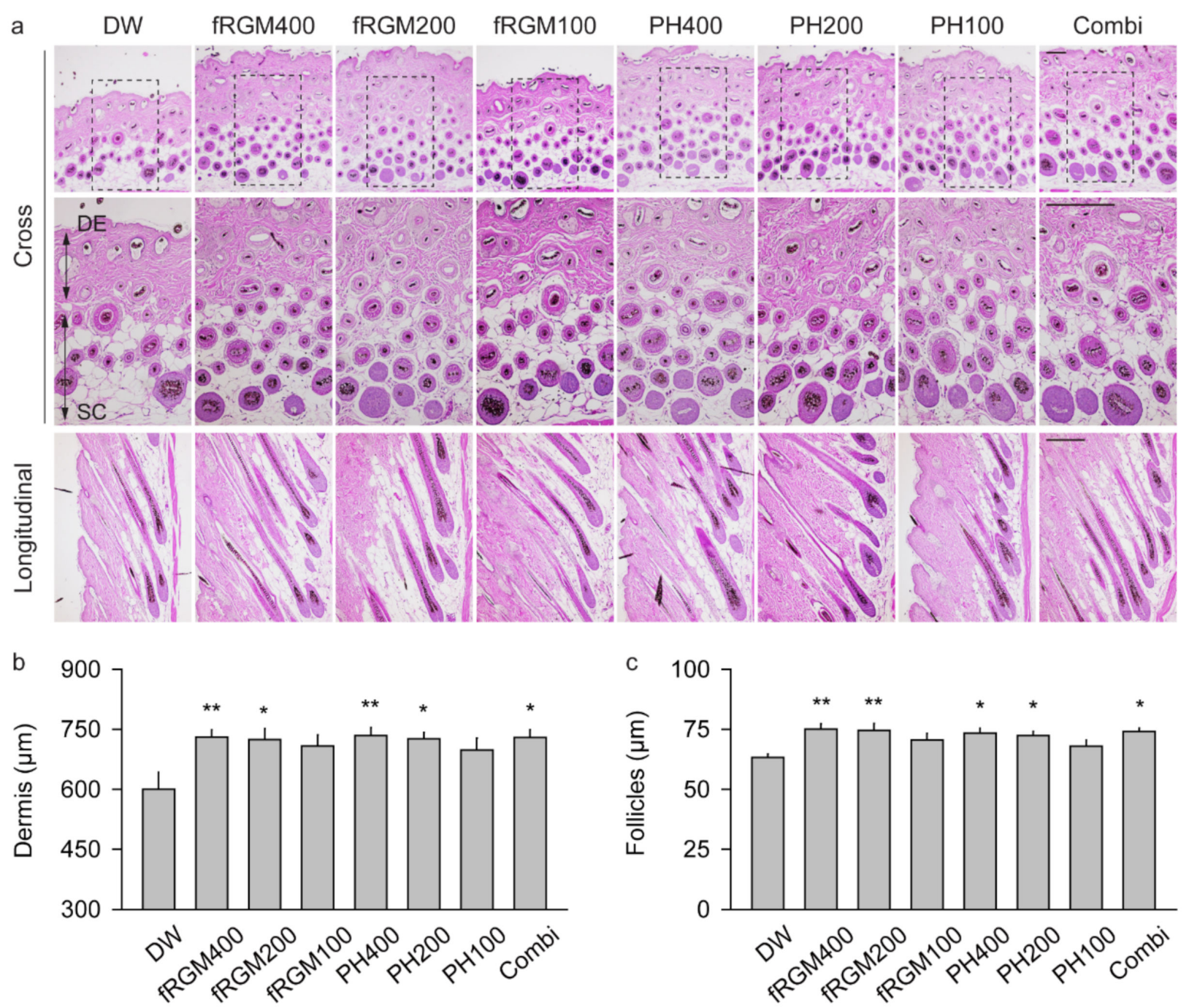

Figure 5. Effects on hair-growth cycle. Tissue sections of the dorsal skin samples were stained in hematoxylin and eosin, and the representative images are shown in (a). In the cross sections, the dotted boxes were high-magnified in the lower. Scale bars indicate $200 \mu \mathrm{m}$. Thickness of the dermis (DE) and diameters of hair follicles in the subcutis (SC) were measured in the cross and longitudinal sections, respectively $(\mathbf{b}, \mathbf{c})$. Values are expressed as means \pm SEM of 6 sample sizes. ${ }^{* *} p<0.01$ and ${ }^{*} p<0.05$ versus the DW group.

The anagen-phase-like follicles with complete root sheath surrounding the bulb were evidently observed in the subcutis of the fRGM, PH and combi groups. One-way ANOVA showed significant differences among the groups for the number of hair follicles in the subcutis $(\mathrm{F}=5.8 ; p<0.01)$ and the total hair follicles $(\mathrm{F}=4.3 ; p<0.01)$, however there was no differences in the number in the dermis (Table 2). The ratio of the follicles in the subcutis to the total follicles was also significantly different among the groups $(\mathrm{F}=2.3 ; p<0.05)$. The post hoc tests versus the DW group revealed significant increases in hair follicles of the subcutis in the fRGM400, fRGM200, PH400, PH200, PH100 and combi groups $(p<0.05)$. The total number of follicles was also significantly increased in the fRGM400, fRGM200, PH400, PH200 and combi groups compared with the DW control $(p<0.05)$. The ratio of the follicles in the subcutis to the total follicle was increased in the PH400 ( $p=0.08)$, PH200 $(p=0.06)$ and combi group $(p=0.07)$; however, it failed to approach the significance. 
Table 2. Histomorphometric analysis for hair follicles.

\begin{tabular}{cccc}
\hline \multirow{2}{*}{ Groups } & \multicolumn{3}{c}{ Numbers of Hair Follicle/mm $\mathbf{~ ( \% ~ i n ~ T o t a l ) ~}$} \\
\cline { 2 - 4 } & Subcutis & Dermis & Total \\
\hline DW & $26.00 \pm 1.68(52.90 \pm 1.39)$ & $23.47 \pm 2.31(47.10 \pm 1.39)$ & $49.47 \pm 3.80(100)$ \\
fRGM400 & $38.30 \pm 1.93^{* *}(58.98 \pm 0.98)$ & $26.54 \pm 1.03(41.02 \pm 0.98)$ & $64.85 \pm 2.69 *(100)$ \\
fRGM200 & $37.34 \pm 1.71^{* *}(59.27 \pm 2.13)$ & $25.68 \pm 1.59(40.73 \pm 2.13)$ & $63.02 \pm 1.91^{*}(100)$ \\
fRGM100 & $33.73 \pm 2.80(56.77 \pm 2.04)$ & $25.32 \pm 1.33(43.23 \pm 2.04)$ & $59.05 \pm 3.45(100)$ \\
PH400 & $39.88 \pm 2.07^{* *}(59.60 \pm 1.83)$ & $26.98 \pm 1.45(40.40 \pm 1.83)$ & $66.86 \pm 2.53 * *(100)$ \\
PH200 & $38.14 \pm 1.81^{* *}(59.93 \pm 0.87)$ & $25.41 \pm 0.77(40.07 \pm 0.87)$ & $63.55 \pm 2.35 *(100)$ \\
PH100 & $35.88 \pm 2.32^{*}(58.98 \pm 1.62)$ & $24.82 \pm 1.33(41.02 \pm 1.62)$ & $60.70 \pm 3.15(100)$ \\
combi & $41.26 \pm 1.05^{* *}(59.83 \pm 1.33)$ & $27.97 \pm 2.06(40.18 \pm 1.33)$ & $69.23 \pm 2.88^{* *}(100)$ \\
\hline
\end{tabular}

The hair follicles were assessed in hematoxylin-eosin stain of the cross sections to the cranio-caudal axis of mice. Values are expressed as mean \pm SEM of 6 sample sizes. ${ }^{* *} p<0.01$ and ${ }^{*} p<0.05$ versus the DW group.

\subsection{Proliferating Effects on Hair Follicle}

The immunostain for Ki-67 as a proliferating marker was few in the DW control in the cross and longitudinal sections. However, a few were observed in the bulb of hair follicles in the subcutis of the treatment groups (Figure 6). Although the immunostained hair follicles were approximately $2-3 \%$, they were observed more in the treatment groups than the DW group. Actually, ANOVA showed significant differences among the groups in the cross $(\mathrm{F}=4.3 ; p<0.01)$ and longitudinal sections $(\mathrm{F}=3.1 ; p<0.05)$. The immunostained follicles were increased by 2.0-fold in the fRGM400, fRGM200, PH400 and fRGM200 groups, and 2.3 -fold in the combi groups in the cross sections, compared with the DW group $(p<0.05)$. They were also increased by 2.6-fold in the fRGM400 and PH400, and 2.8-fold in the combi in the longitudinal sections $(p<0.05)$.

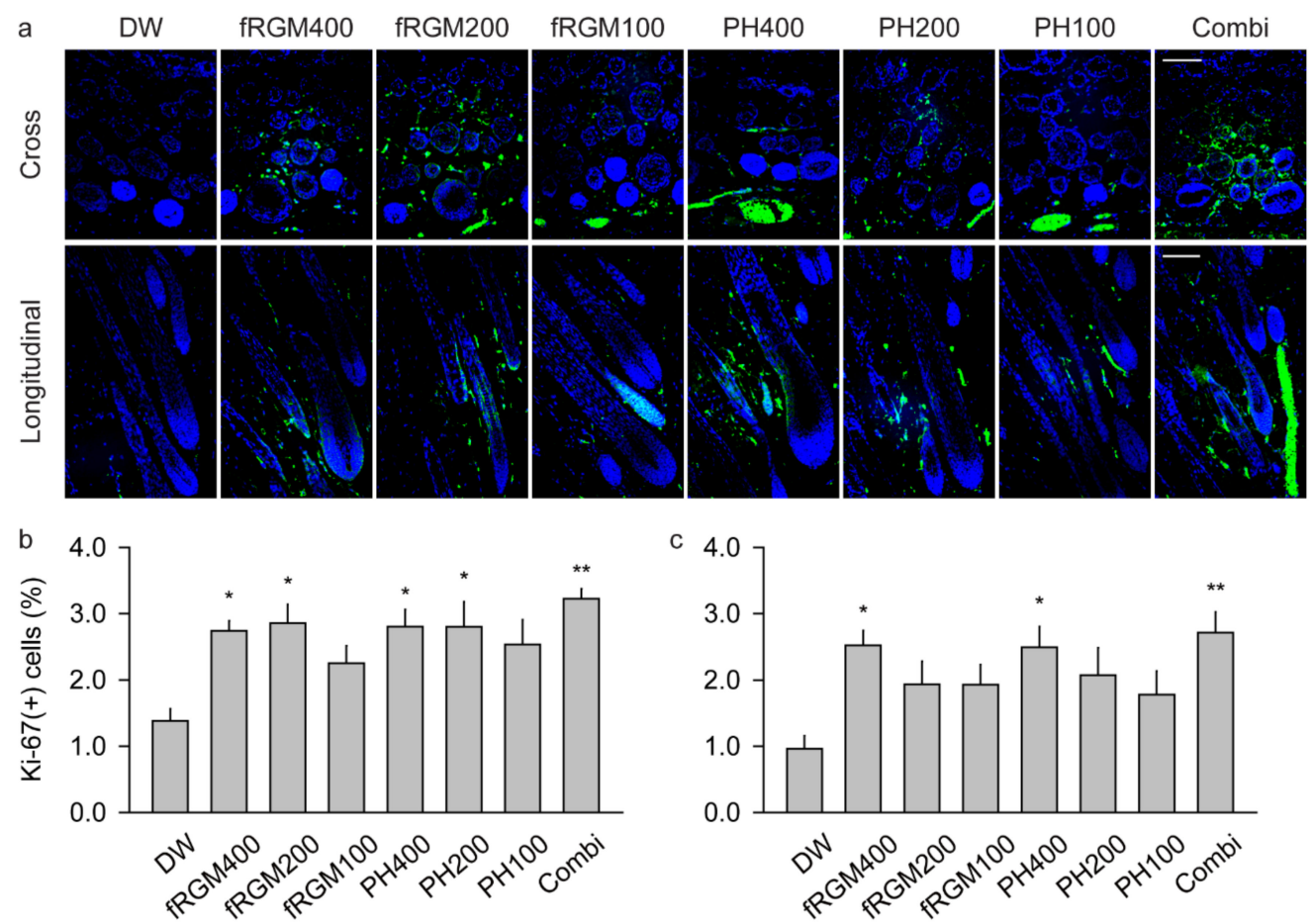

Figure 6. Effects on cellular proliferation. The serial sections were immunostained for Ki-67 as a maker for proliferation (green) and counterstained with 4,6-diamidino-2-phenylindole (blue) (a). Scale bars indicate $100 \mu \mathrm{m}$. The immunostained cells were assessed in the cross (b) and longitudinal sections (c) and expressed as a percentage of total follicle cells. Values are mean \pm SEM of 6 sample sizes. ${ }^{* *} p<0.01$ and ${ }^{*} p<0.05$ versus the DW group. 


\section{Discussion}

Hair growth was rapidly increased from day 9 after hair removal and waxing, similar with other studies [28-30]. The kinetic hair growth on each day was not significantly different among the groups, probably due to small sample sizes or limitation of the measurements to detect the subtle changes on each day. In addition, the individual differences shown in the same group might be involved in the incomplete anagen synchronization, which may result in a failure to approach the significant differences. However, the higher doses of fRGM and PH increased the final grown hair regions on day 0 to 15 post-treatment. Hair length and thickness increased for all doses of fRGM and PH, and hair weight increased for the treatment groups except the low-dose groups. The combination treatments also showed beneficial effects on hair growth and hair quality, even though the combination dose was half the high doses of fRGM and PH. Hair weighing and microscopic measurements of hair length and width are generally used in clinical studies to evaluate the effects of drugs or cosmetic molecules as a hair tonic [33]. Further, clinical diagnosis for hair loss needs scalp biopsy to observe the follicular quantity and diameter and other morphometric data for abnormal hair cell growth. The current histopathological analyses revealed that components of fRGM and PH contribute to increasing follicular numbers, diameters and proliferation, in particular in the hair follicles located at the deep subcutis. These suggest that the fRGM and PH may promote hair-growth cycle, probably by enhancing anagen-phased cell division, as well as functions as a hair tonic.

The length and thickness of a hair shaft depend on the duration of the hair follicular cycle, in particular duration of anagen phase [34]. Indeed, androgenetic alopecia produces thinning of scalp hair, and the miniaturization of hair follicles involves shortened anagen phase and reduced sizes of the hair matrix [3]. In this context, enhancing the induction of anagen or prolonging the duration can be a therapeutic strategy for hair loss. The fRGM, PH and the combination increased the hair follicles closed to the deep layer of subcutis, suggesting promoting effects on development of the follicles in anagen III to VI or catagen stages [34]. It might result in the increased total hair follicles in the treatments of the higher doses of fRGM, PH and the combination. The increases in anagen-phased follicles might be due to induction of an earlier anagen phase or transition of hair growth from telogen to anagen [35,36]. The transformation from telogen- to anagen-phased hair follicles undergoes through rapid proliferation of follicular keratinocytes and elongation and thickening of the hair shaft [37]. Here, considering that the fRGM and PH and the combination increased $\mathrm{Ki}-67$ positive cells in the bulb of the subcutis, the anagen-like hair follicles could be regenerated by rapid proliferation of the matrix keratinocytes, producing increased follicular sizes for a new hair fiber. It suggests that the components contained in the fRGM and PH may contribute to induction of anagen-phased follicles and improve the altered hair-growth cycles or destroyed hair follicles in hair loss $[2,38]$.

Hair growth is regulated by various hormones, cytokines and growth factors. For example, androgens reduce the anagen phase, increasing the other phased follicles and delaying the telogen to anagen transitions [39]. Basic FGF promotes proliferation of the papilla cells, contributing to elongate the hair shaft [40], and hepatocyte growth factor and vascular endothelial growth factor (VEGF) stimulate growth of the hair follicle and hair shaft [41,42]. The growth factors and others including epidermal growth factor, keratinocyte growth factor (KGF), insulin-like growth factor-I and transforming growth factor have shown mitogenic and motogenic effects on keratinocyte [43]. The traditional polyherb formula used here is composed of seven herbs, and the components may contribute to enhancing the hair-growth cycle. Cornu cervi pantotrichum and Eclipta prostrata facilitate hair growth through upregulation of FGF-7 (KGF) and FGF-5 [16,17]. In red ginseng, Rb1 and Rd stimulate proliferation of hair follicle cells [15,27], and other phenolic compounds and vitamins give specific support to the maintenance of hair follicle health [44]. In particular, vitamin $C$ is known to improve blood vessel formation, increasing blood flow in the scalp by stimulating VEGF synthesis [45]. There is a report showing promoting potentials of $\mathrm{Rb} 1$ on hair growth through activating extracellular signal-regulated kinase and AKT signaling 
pathways [10]. The mitogen-activated pathway plays an important role in cell growth and proliferation [46,47]. Further, Eclipta prostrata, Polygonum multiflorum Thunberg and red ginseng have been reported to inhibit $5-\alpha$ reductase $[10,11,19]$. The paracrine factors have been assumed to stimulate or regulate hair growth and the proliferation of hair matrix cells, and further studies need to clarify the exact mechanisms.

As increases in the concern on the well-being in life, the demands to improve one's appearance instigate the consumption of functional products for hair health. Further, alopecia is a widespread condition affecting both sexes: $50 \%$ over 50 years of age in males and about $50 \%$ in females [6]. The clinical signs are usually milder in females than males; however, hair loss creates emotional stress in both. Most of the hair-loss-related disorders need daily controls, which increases interests in functional shampoo products in the market because of an easy cure. Although a variety of medicated shampoos are commercially available, the therapeutic benefits are ambiguous. Further, thousands of natural products including traditional polyherbs are used as hair tonics, based on traditional experiences rather than the scientific effectiveness. Several herbs have shown beneficial effects on hair loss as a complementary and alternative medicine [48,49], while effectiveness of many other herbs needs to be clarified. Here, topical treatments of the fRGM and PH for 2 weeks showed promoting effects on hair growth, probably by enhancing the induction of anagen or prolonging the duration. Interestingly, the fRGM contained a very low concentration of ginsenosides compared with those of the red ginseng [50]; however, it still had the functional effects on hair growth as an additive component rather than the byproduct. Given that the fRGM contained few toxic compounds, and all treatments had little dermatological side effects, it is expected to use fRGM in combination with the effective traditional polyherb formula for the synergistic effects.

\section{Conclusions}

In the present study, the hair-depilated mice model showed individual differences even in hair growth in the same treatment group, probably due to the incomplete anagen synchronization. Although there were no significant differences in hair-covering regions on a specific day during the treatments, the fRGM and PH significantly increased the regions that were finally regrown on days 0 to 14 and also increased hair length, thickness and weight. In addition, follicular numbers, thickness and proliferation were observed in deep layer of the subcutis, mainly composed of anagen-phased follicles. The beneficial effects were greater in the high doses of fRGM and PH and the combi groups. It suggests that the fRGM and PH may promote hair growth via anagen-phased cell divisions, along with functions as a hair tonic. Future study needs to clarify the promoting effects on the growth cycle in proper models and the relevant mechanisms. These provide useful information for guiding the use of fRGMs and PH in patients with hair loss.

Author Contributions: Conceptualization and investigation, P.H.S., G.-R.P. and C.-H.S.; project administration and funding acquisition, P.H.S., S.-K.K. and C.-H.S.; writing-original draft preparation and visualization, P.H.S. and C.-H.S.; methodology and formal analysis, G.-R.P., Y.-H.K., D.H.J. and S.-K.K.; data curation, D.H.J., P.H.S. and C.-H.S.; resources, Y.-H.K.; validation and supervision, S.-K.K. and C.-H.S. All authors have read and agreed to the published version of the manuscript.

Funding: This work was partly supported by the Technology Development Program of MSS (C0237051), the National Research Foundation of Korea (NRF) grant funded by the Korea Government (MSIT) (grant number 2018R1A5A2025272), and the Basic Science Research Program through the NRF funded by the Ministry of Education (grant numbers 2017R1D1A3B03031498).

Institutional Review Board Statement: All animal experiments were conducted according to the national regulations of the usage and welfare of laboratory animals and approved by the Daegu Haany University-Institutional Animal Care and Use Committee (Gyeongsan, Korea, approval number: DHU2015-019).

Informed Consent Statement: Not applicable.

Data Availability Statement: The data presented in this study are available in article. 
Acknowledgments: Phil Hyun Song and Gyu-Ryeul Park contributed equally to this. We appreciate Cheol-Min Jeon for helping preparation of the fRGM.

Conflicts of Interest: The authors declare no conflict of interest.

\section{References}

1. Mulinari-Brenner, F.; Bergfeld, W.F. Hair loss: An overview. Derm. Nurs. 2001, 13, 269-272, 277-278.

2. Paus, R.; Cotsarelis, G. The biology of hair follicles. N. Engl. J. Med. 1999, 341, 491-497. [CrossRef] [PubMed]

3. Trueb, R.M. Molecular mechanisms of androgenetic alopecia. Exp. Gerontol. 2002, 37, 981-990. [CrossRef]

4. Trueb, R.M.; Dias, M. Alopecia Areata: A Comprehensive Review of Pathogenesis and Management. Clin. Rev. Allergy Immunol. 2018, 54, 68-87. [CrossRef] [PubMed]

5. Williamson, D.; Gonzalez, M.; Finlay, A.Y. The effect of hair loss on quality of life. J. Eur. Acad. Derm. Venereol. 2001, 15, 137-139. [CrossRef] [PubMed]

6. Rogers, N.E.; Avram, M.R. Medical treatments for male and female pattern hair loss. J. Am. Acad. Dermatol. 2008, 59, 547-566. [CrossRef] [PubMed]

7. Lee, S.W.; Juhasz, M.; Mobasher, P.; Ekelem, C.; Mesinkovska, N.A. A Systematic Review of Topical Finasteride in the Treatment of Androgenetic Alopecia in Men and Women. J. Drugs Derm. 2018, 17, 457-463.

8. Hong, Y.J.; Kim, N.; Lee, K.; Hee Sonn, C.; Eun Lee, J.; Tae Kim, S.; Ho Baeg, I.; Lee, K.M. Korean red ginseng (Panax ginseng) ameliorates type 1 diabetes and restores immune cell compartments. J. Ethnopharmacol. 2012, 144, 225-233. [CrossRef]

9. Kim, J.Y.; Park, J.Y.; Kang, H.J.; Kim, O.Y.; Lee, J.H. Beneficial effects of Korean red ginseng on lymphocyte DNA damage, antioxidant enzyme activity, and LDL oxidation in healthy participants: A randomized, double-blind, placebo-controlled trial. Nutr. J. 2012, 11, 47. [CrossRef]

10. Park, G.H.; Park, K.Y.; Cho, H.I.; Lee, S.M.; Han, J.S.; Won, C.H.; Chang, S.E.; Lee, M.W.; Choi, J.H.; Moon, K.C.; et al. Red ginseng extract promotes the hair growth in cultured human hair follicles. J. Med. Food 2015, 18, 354-362. [CrossRef]

11. Kim, S.N.; Kim, S.; Hong, Y.D.; Park, H.; Shin, S.H.; Kim, A.R.; Park, B.C.; Shin, S.S.; Park, J.S.; Park, M.; et al. The ginsenosides of Panax ginseng promote hair growth via similar mechanism of minoxidil. J. Dermatol. Sci. 2015, 77, 132-134. [CrossRef] [PubMed]

12. Kim, J.-H.; Yi, S.-M.; Choi, J.-E.; Son, S.-W. Study of the efficacy of Korean red ginseng in the treatment of androgenic alopecia. J. Ginseng. Res. 2009, 33, 223-228.

13. Yang, W.; Qiao, X.; Li, K.; Fan, J.; Bo, T.; Guo, D.A.; Ye, M. Identification and differentiation of Panax ginseng, Panax quinquefolium, and Panax notoginseng by monitoring multiple diagnostic chemical markers. Acta Pharm. Sin. B 2016, 6, 568-575. [CrossRef] [PubMed]

14. Kim, S.H.; Jeong, K.S.; Ryu, S.Y.; Kim, T.H. Panax ginseng prevents apoptosis in hair follicles and accelerates recovery of hair medullary cells in irradiated mice. In Vivo 1998, 12, 219-222.

15. Matsuda, H.; Yamazaki, M.; Asanuma, Y.; Kubo, M. Promotion of hair growth by ginseng radix on cultured mouse vibrissal hair follicles. Phytother. Res. 2003, 17, 797-800. [CrossRef]

16. Lee, S.Y.; Lee, D.J.; Kwon, K.; Lee, C.H.; Shin, H.J.; Kim, J.E.; Ha, K.T.; Jeong, H.S.; Seo, H.S. Cornu cervi pantotrichum Pharmacopuncture Solution Facilitate Hair Growth in C57BL/6 Mice. J. Pharmacopunct. 2016, 19, 122-128. [CrossRef]

17. Lee, K.H.; Choi, D.; Jeong, S.I.; Kim, S.J.; Lee, C.H.; Seo, H.S.; Jeong, H.S. Eclipta prostrata promotes the induction of anagen, sustains the anagen phase through regulation of FGF-7 and FGF-5. Pharm. Biol. 2019, 57, 105-111. [CrossRef]

18. Leem, J.; Jung, W.; Kim, Y.; Kim, B.; Kim, K. Exploring the combination and modular characteristics of herbs for alopecia treatment in traditional Chinese medicine: An association rule mining and network analysis study. BMC Complement. Altern. Med. 2018, 18, 204. [CrossRef]

19. Zhang, B.; Zhang, R.W.; Yin, X.Q.; Lao, Z.Z.; Zhang, Z.; Wu, Q.G.; Yu, L.W.; Lai, X.P.; Wan, Y.H.; Li, G. Inhibitory activities of some traditional Chinese herbs against testosterone 5alpha-reductase and effects of Cacumen platycladi on hair re-growth in testosterone-treated mice. J. Ethnopharmacol. 2016, 177, 1-9. [CrossRef]

20. Lee, S.D.; Yoo, G.; Chae, H.J.; In, M.-J.; Oh, N.-S.; Hwang, Y.K.; Hwang, W.I.; Kim, D.C. Lipid-soluble extracts as the main source of anticancer activity in ginseng and ginseng marc. J. Am. Oil Chem. Soc. 2009, 86, 1065-1071. [CrossRef]

21. Lim, T.S.; Na, K.; Choi, E.M.; Chung, J.Y.; Hwang, J.K. Immunomodulating activities of polysaccharides isolated from Panax ginseng. J. Med. Food 2004, 7, 1-6. [CrossRef] [PubMed]

22. Yoo, G.; Lee, S.D.; In, M.-J.; Hwang, W.I.; Lee, K.S.; Lee, E.S.; Kim, D.C.; Chae, H.J. An alternative sequential extraction process for maximal utilization of bioactive components from Korean red ginseng. Korean J. Chem. Eng. 2009, 26, 1094-1097. [CrossRef]

23. Jung, H.-W.; Kim, J.-E.; Seo, J.-H.; Lee, S.-P. Physicochemical and antioxidant properties of red ginseng marc fermented by Bacillus subtilis HA with mugwort powder addition. J. Korean Soc. Food Sci. Nutr. 2010, 39, 1391-1398. [CrossRef]

24. Chui, C.H.; Cheng, G.Y.; Ke, B.; Lau, F.Y.; Wong, R.S.; Kok, S.H.; Fatima, S.; Cheung, F.; Cheng, C.H.; Chan, A.S.; et al. Growth inhibitory potential of effective microorganism fermentation extract (EM-X) on cancer cells. Int. J. Mol. Med. 2004, 14, 925-929. [CrossRef]

25. Deiana, M.; Dessi, M.A.; Ke, B.; Liang, Y.F.; Higa, T.; Gilmour, P.S.; Jen, L.S.; Rahman, I.; Aruoma, O.I. The antioxidant cocktail effective microorganism $X(E M-X)$ inhibits oxidant-induced interleukin-8 release and the peroxidation of phospholipids in vitro. Biochem. Biophys. Res. Commun. 2002, 296, 1148-1151. [CrossRef] 
26. Datla, K.P.; Bennett, R.D.; Zbarsky, V.; Ke, B.; Liang, Y.F.; Higa, T.; Bahorun, T.; Aruoma, O.I.; Dexter, D.T. The antioxidant drink effective microorganism-X (EM-X) pre-treatment attenuates the loss of nigrostriatal dopaminergic neurons in 6-hydroxydopaminelesion rat model of Parkinson's disease. J. Pharm. Pharm. 2004, 56, 649-654. [CrossRef]

27. Li, Z.; Li, J.J.; Gu, L.J.; Zhang, D.L.; Wang, Y.B.; Sung, C.K. Ginsenosides Rb1 and Rd regulate proliferation of mature keratinocytes through induction of p63 expression in hair follicles. Phytother. Res. 2013, 27, 1095-1101. [CrossRef]

28. Choi, J.S.; Jeon, M.H.; Moon, W.S.; Moon, J.N.; Cheon, E.J.; Kim, J.W.; Jung, S.K.; Ji, Y.H.; Son, S.W.; Kim, M.R. In vivo hair growth-promoting effect of rice bran extract prepared by supercritical carbon dioxide fluid. Biol. Pharm. Bull. 2014, $37,44-53$. [CrossRef]

29. Hou, I.C.; Oi, Y.; Fujita, H.; Yano, Y.; Fukami, H.; Yoshikawa, M. A Hair Growth-Promoting Effect of Chinese Black Tea Extract in Mice. Biosci. Biotechnol. Biochem. 2013, 77, 1606-1607. [CrossRef]

30. Junlatat, J.; Sripanidkulchai, B. Hair growth-promoting effect of Carthamus tinctorius floret extract. Phytother. Res. PTR 2014, 28, 1030-1036. [CrossRef]

31. Yoon, J.I.; Al-Reza, S.M.; Kang, S.C. Hair growth promoting effect of Zizyphus jujuba essential oil. Food Chem. Toxicol. Int. J. Publ. Br. Ind. Biol. Res. Assoc. 2010, 48, 1350-1354. [CrossRef] [PubMed]

32. Kim, K.H.; Park, S.J.; Lee, Y.J.; Lee, J.E.; Song, C.H.; Choi, S.H.; Ku, S.K.; Kang, S.J. Inhibition of UVB-Induced Skin Damage by Exopolymers from Aureobasidium pullulans SM-2001 in Hairless Mice. Basic Clin. Pharmacol. Toxicol. 2015, 116, 73-86. [CrossRef] [PubMed]

33. Hillmann, K.; Blume-Peytavi, U. Diagnosis of hair disorders. Semin. Cutan. Med. Surg. 2009, 28, 33-38. [CrossRef] [PubMed]

34. Muller-Rover, S.; Handjiski, B.; van der Veen, C.; Eichmuller, S.; Foitzik, K.; McKay, I.A.; Stenn, K.S.; Paus, R. A comprehensive guide for the accurate classification of murine hair follicles in distinct hair cycle stages. J. Investig. Dermatol. 2001, 117, 3-15. [CrossRef] [PubMed]

35. Datta, K.; Singh, A.T.; Mukherjee, A.; Bhat, B.; Ramesh, B.; Burman, A.C. Eclipta alba extract with potential for hair growth promoting activity. J. Ethnopharmacol. 2009, 124, 450-456. [CrossRef] [PubMed]

36. Paus, R.; Müller-Röver, S.; van der Veen, C.; Maurer, M.; Eichmüller, S.; Ling, G.; Hofmann, U.; Foitzik, K.; Mecklenburg, L.; Handjiski, B. A comprehensive guide for the recognition and classification of distinct stages of hair follicle morphogenesis. $J$. Investig. Dermatol. 1999, 113, 523-532.

37. Hardy, M.H. The secret life of the hair follicle. Trends Genet. 1992, 8, 55-61. [CrossRef]

38. Stenn, K.S.; Paus, R. Controls of hair follicle cycling. Physiol. Rev. 2001, 81, 449-494. [CrossRef]

39. Buhl, A.E.; Conrad, S.J.; Waldon, D.J.; Brunden, M.N. Potassium channel conductance as a control mechanism in hair follicles. J. Investig. Dermatol. 1993, 101, S148-S152. [CrossRef]

40. Katsuoka, K.; Schell, H.; Wessel, B.; Hornstein, O.P. Effects of epidermal growth factor, fibroblast growth factor, minoxidil and hydrocortisone on growth kinetics in human hair bulb papilla cells and root sheath fibroblasts cultured in vitro. Arch. Derm. Res. 1987, 279, 247-250. [CrossRef]

41. Jindo, T.; Tsuboi, R.; Takamori, K.; Ogawa, H. Local injection of hepatocyte growth factor/scatter factor (HGF/SF) alters cyclic growth of murine hair follicles. J. Investig. Dermatol. 1998, 110, 338-342. [CrossRef] [PubMed]

42. Yano, K.; Brown, L.F.; Detmar, M. Control of hair growth and follicle size by VEGF-mediated angiogenesis. J. Clin. Investig. 2001, 107, 409-417. [CrossRef] [PubMed]

43. Seeger, M.A.; Paller, A.S. The Roles of Growth Factors in Keratinocyte Migration. Adv. Wound Care (New Rochelle) 2015, 4, 213-224. [CrossRef] [PubMed]

44. Dzialo, M.; Mierziak, J.; Korzun, U.; Preisner, M.; Szopa, J.; Kulma, A. The Potential of Plant Phenolics in Prevention and Therapy of Skin Disorders. Int. J. Mol. Sci. 2016, 17, 160. [CrossRef]

45. Semalty, M.; Semalty, A.; Joshi, G.P.; Rawat, M.S. Hair growth and rejuvenation: An overview. J. Dermatol. Treat. 2011, 22, 123-132. [CrossRef]

46. Li, W.; Man, X.Y.; Li, C.M.; Chen, J.Q.; Zhou, J.; Cai, S.Q.; Lu, Z.F.; Zheng, M. VEGF induces proliferation of human hair follicle dermal papilla cells through VEGFR-2-mediated activation of ERK. Exp. Cell Res. 2012, 318, 1633-1640. [CrossRef]

47. Zhang, W.; Liu, H.T. MAPK signal pathways in the regulation of cell proliferation in mammalian cells. Cell Res. 2002, 12, 9-18. [CrossRef]

48. Van den Biggelaar, F.J.; Smolders, J.; Jansen, J.F. Complementary and alternative medicine in alopecia areata. Am. J. Clin. Derm. 2010, 11, 11-20. [CrossRef]

49. Bassino, E.; Gasparri, F.; Munaron, L. Protective Role of Nutritional Plants Containing Flavonoids in Hair Follicle Disruption: A Review. Int. J. Mol. Sci. 2020, 21, 523. [CrossRef]

50. Lee, S.M.; Bae, B.S.; Park, H.W.; Ahn, N.G.; Cho, B.G.; Cho, Y.L.; Kwak, Y.S. Characterization of Korean Red Ginseng (Panax ginseng Meyer): History, preparation method, and chemical composition. J. Ginseng. Res. 2015, 39, 384-391. [CrossRef] 